\title{
LEGAL PROVISION OF INFORMATION SECURITY AS AN INTEGRAL FACTOR IN THE CONTEXT OF A PANDEMIC
}

${ }^{1}$ Rasulev Abdulaziz, Professor of the Department of Crime prevention of the Academy of the Ministry of Internal Affairs of the Republic of Uzbekistan, Doctor of Science in Law

${ }^{2}$ Sobirov Shokhrukhbek, Head of department of the research institute for Legal Policy under Ministry of Justice of the Republic of Uzbekistan

${ }^{3}$ Sadullayev Gayrat, Teacher of the Department of Crime prevention of the Academy of the Ministry of Internal Affairs of the Republic of Uzbekistan
G OPEN ACCESS The American Journal of Social Science and Education Innovations JUNE 2020

Page No. : 58-63

Volume-II Issue-VI PUBLISHED: 30 JUNE 2020 www.usajournalshub.com/in dex.php/tajssei Copyright: Original content from this work may be used under the terms of the CreativeCommons Attribution 4.0 licence.

Abstract: This article analyzes trends in the use of the Internet, taking into account the spread of the coronavirus pandemic, the problems that arise in practice and their possible consequences. Based on the analysis, the author has developed appropriate recommendations and suggestions.

Key words: Internet, crime, information security, coronavirus, Internet culture, virtual space, blogger.

\section{Introduction}

Today, during the period of quarantine due to the coronavirus pandemic around the world, the Internet space has become a central platform for social, cultural, socio-economic, as well as legal relations. It should be noted that at the same time, the Internet has become the main field of action for committing various types of crimes. Thus, the pandemic that took everyone by surprise created a favorable environment for uncontrolled and irresponsible use of the Internet. Now the spread of «fakes», slander and insults on the Internet has become very popular and, unfortunately, already a common event. At a time of undeniable influence of bloggers and other Internet activists on the formation of public 
opinion in the information space, it is impossible to underestimate their impact on the consciousness of users of social networks.

In particular, they undoubtedly have a negative impact on young people, who now spend almost all their active time in virtual space in the context of distance learning. Therefore, the current issue on the agenda is how the pandemic affected the use of the Internet and the behavior of people in the virtual space.

First, information that does not correspond to reality or discredits the honor and dignity of others has begun to spread on the Internet.

As a result of the spread of the coronavirus pandemic, the Internet has become a key resource for people to quickly get information. It is during the coronavirus in the virtual space increased the flow of various information, which also increased the volume of unprocessed or false information.

Fakes published on the Internet have become difficult to distinguish due to the following reasons:

fake news is often disguised as regular news, which is why it is easy to cause panic;

users trust a source with a large number of subscribers, so the bulk, or rather every fifth fake news falls under existing websites that can easily be found on Google ;

the presence of a huge array of fakes, which makes it difficult to determine reliable, and therefore legitimate information. For example, in 2019, the analytical center «Medialogiya» revealed an increase in fake news reports by $30 \%$, in 2018 , the use of the phrase «fake news» in the Internet space increased by $365 \%$. All this certainly indicates that fake news is entering the usual use of the information space.

In our opinion, these problems require consistent, but at the same time not repressive measures, in particular, they require the creation of information and analytical Centers for monitoring the media and social networks, as well as other resources on the Internet under the Public Fund for support and development of national mass media, established at the end of January 2020.

Secondly, the predominant content on the Internet clearly indicates a low level of legal awareness, and also contributes to a decrease in the level of trust on the Internet.

In recent months, the Internet has seen a certain decline in the level of legal awareness of the population. Examples of this are numerous instances of insubordination to authorities, which are expressed in violation of the rules of quarantine, established prohibitions, as well as public peace and security. Thus, it is regrettable to note that 51,182 administrative offences were committed during the first month of quarantine, which indicates that certain categories of offenders did not accept or ignore the established prohibitions. Such offences may seem insignificant at first glance, but they may become a prerequisite for more serious crimes in the future. Also of particular concern is the low culture and nihilism of individuals who are celebrities and undoubtedly enjoy a certain authority among ordinary people. These individuals not only set a bad example by their actions, but also create a sense of collective irresponsibility among the population.

Evidence of low legal awareness is also insufficient knowledge and worldview. Analysis of texts on the Internet has shown that every year the number of cases of using illiterate and sometimes absolutely absurd, primitive texts is growing rapidly. According to the site https://hype.tech almost every internet-user makes mistakes, including abbreviations and other errors. About 2 percent of users can't correctly identify the endings of words. It is also 
worth noting that public criticism of their illiteracy sometimes causes discontent, great indignation of the Internet community, due to the overwhelming number of them. Such cases may indicate that the Internet to a certain extent «encourages» the illiteracy of users.

Today, one of the most common problems of trust in the Internet has become cyber fraud. In the last two or three years, the number of scams in the Internet segment has increased significantly for a number of reasons. So, with the emergence and growth of mass popularity of such a phenomenon as social networks, the number of Internet users who came to the Internet in order to search for their friends and acquaintances has also increased, which is actively used by fraudsters themselves, luring «victims» into virtual relationships. On the other hand, the spread of such social services has become a kind of discredit to the trust of users, especially in cases where there are cases of spam and phishing that violate information security and contribute to the extortion of electronic money on the Internet.

In general, the problem of legal awareness and trust in the Internet is a complex problem. In this regard, it is necessary to create a special Internet culture on the part of users of the virtual space by conducting courses and introductory lessons (including video lessons that can be viewed offline), electronic and printed brochures and other visual materials.

Third, the information available on the Internet can cause various kinds of conflicts to be ignited.

In the context of global freedom of speech and the large-scale expansion of the use of information and communication technologies, it is almost impossible to ensure the reliability and public utility of the information distributed. It is known that today absolutely active Internet users, and especially bloggers, have the most impulsive and real impact on public consciousness, a clear example of this is the media. At the same time, bloggers, unlike other media, can post information of various kinds. According to statistics, users prefer to use the Internet the most to access political information (54\%), medical information (46\%), or information about government authorities (42\%). Most of all, in the world, getting political information from the Internet is observed in the Arab countries: Tunisia (72\%), Libya (70\%) and Egypt (68\%). However, information about the activities of terrorist organizations is not excluded. YouTube, Instagram, Facebook, Twitter, and Friendica are the main propagandists of the Islamic state that effectively use Western communication technologies to cover the war zone and recruit foreign citizens. Thousands of accounts, the use of Twitter Storm during combat operations to create panic behind enemy lines, thousands of videos of supporters of the movement and tens of millions of views attest to the destructive power of the impact of information. These media resources mainly operate on the world wide web due to its total availability.

In our view, the fight against this negative phenomenon is effective only if law enforcement officers are properly qualified, which requires the creation of a specialized center for countering cyber threats as a special unit of the State Security Service of the Republic of Uzbekistan, which will be assigned the task of taking measures to prevent and prevent virtual threats to the security of individuals, society and the state.

Fourth, the conditions of the pandemic clearly highlighted the inconsistencies of legislation in terms of regulating relations on the Internet.

The period of quarantine in connection with the pandemic has shown that the only thing 
worse than a coronavirus can be a panic due to a coronavirus. In this regard, the rapid response measure was № 5969 «On priority measures to mitigate the negative impact on the economy of the coronavirus pandemic and global crisis phenomena» dated March 19, 2020.

Every day, various social networks, messengers or websites on the Internet contain fake news about mass infection and death of people, about the depletion of food resources, about the introduction of a curfew or state of emergency. Law enforcement agencies have to deal with this problem 24 hours a day. For several months now, Governments of all countries have been reminding their populations of their responsibility for spreading false information. Thus, the Prime Minister of the Republic of Uzbekistan A. Aripov held a meeting on the prevention of coronavirus in early 2020 and indicated that the state is taking measures to prevent and prevent the spread of the disease. In turn, as the head of the Special Republican Commission for the preparation of a Program of measures to prevent the import and spread of coronavirus in the Republic of Uzbekistan, the Prime Minister takes a number of important measures and rules, compliance with which is aimed at preventing the spread of coronavirus.

A number of Internet resources and social networks have launched their own information campaigns to inform users about the situation, which are confirmed by official sources. For example, the Ministry of health of the Republic of Uzbekistan has launched a website to promptly inform the population of official information about coronavirus in Uzbekistan coronavirus.uz and his channel in the telegram messenger «Coronavirus Info». All these measures indicate the priority of providing the population with reliable information about the status of measures taken during the coronavirus pandemic.

Around the world, the Internet has increased the spread of fakes about the coronavirus. So, in Austria, an audio recording was distributed, in which a woman says in an agitated voice that she is in the hospital, and everyone who has severe symptoms of the coronavirus was taking ibuprofen. The woman introduces herself as Pauline, the mother of a girl named Poldy. This is fake: doctors did not name ibuprofen as the cause of activation of the coronavirus, but users willingly shared the record, misleading their loved ones.

One of the problems during the coronavirus was the lack of legislation establishing responsibility for the dissemination of false information about the coronavirus, as well as failure to comply without good reason in the conditions of the occurrence and spread of quarantine and other dangerous infections of the requirements for medical examination, treatment and arrival in places designated for quarantine and non-abandonment of these places in the established period, disclosure of information about individuals, with whom there was contact and places of visit during the period of risk of infection with the disease, as well as other legal requirements of the state sanitary supervision authorities. The solution to this problem, though belated, was the amendments to article 54 Liabilities and article $257^{1}$ of the criminal code of the Republic of Uzbekistan, as well as establishing the criminal liability of dissemination of untrue information about the spread of quarantine and other dangerous for human infections in the emergence and spread of quarantine and other dangerous for human infections.

It should be noted that one of the problems of today's information space is the freedom and irresponsibility of some bloggers. Of course, the free use of information and communication technologies and the Internet can lead to certain negative consequences. 
Like any other state, the Republic of Uzbekistan also intends to address the issue of preventing the spread of negative content. Considering the problems of the negative impact of the Internet on people's minds, we can note that in our doctoral dissertation and scientific articles published within it, we pointed out a comprehensive approach to solving problems. For this purpose, we consider it appropriate to adopt a State program for the formation of Internet culture, which includes a set of measures - conducting trainings, special courses in educational institutions, preparing and distributing propaganda materials (flyers, stands, presentations) in the media and the Internet. In these circumstances, social measures are particularly important, which are aimed at creating awareness among people, in particular young people, of the dangers and negative consequences of crimes in the field of information technology and security.

At the same time, the Association of young people should be voluntary and independent, and not be dictated in an administrative way from above. It seems appropriate to create a «club of initiative patriots-programmers», which will be a platform for talented and creative young people with the necessary knowledge and skills in the field of information and communication technologies and cybersecurity, a discussion environment and a visual platform for recruitment in the future. In our opinion, this club should be created under the youth Union of Uzbekistan with the support of the Ministry of Education, the Ministry of education, the Ministry of Innovative Development with the involvement of leading specialists, experts and analysts. The creation of this club can serve as a bright case of an open dialogue with young people, a kind of preventive center for the prevention and identification of persons with a tendency to commit information offenses, as well as their education in the spirit of patriotism, respect for the law and participation in the construction of a developed state and information society.

The second side of the problem is the lack of specific measures of legal responsibility. At the same time, the legislation provides for existing prohibitions on «using» the Internet in a negative sense. According to article $12^{1}$ Of the law of the Republic of Uzbekistan «On informatization», the owner of a website and (or) a website page, including a blogger, is obliged to prevent the use of their website and (or) a website page in the world information network of the Internet, which contains publicly available information, in order to:

calling for forcible changes to the existing constitutional order and territorial integrity of the Republic of Uzbekistan;

propaganda of war, violence and terrorism, as well as ideas of religious extremism, separatism and fundamentalism;

disclosure of information constituting state secrets or other secrets protected by law; dissemination of information that incites national, racial, ethnic or religious hostility, as well as discrediting the honor and dignity or business reputation of citizens, allowing interference in their private life;

promotion of narcotic drugs, psychotropic substances and precursors;

propaganda of pornography;

committing other actions that entail criminal and other liability in accordance with the law.

However, the above actions do not entail liability under either the administrative Code or the criminal code of the Republic of Uzbekistan, so appropriate measures should be taken to establish responsibility, namely administrative and criminal liability for illegal actions of 
the blogger. In turn, it is necessary to provide for the possibility of closing websites or other resources on the Internet only by a court decision, since the court is the final instance that administers justice.

Thus, in conclusion, it should be noted that the main key step in solving the abovementioned problems is the formation of a kind of Internet culture, the implementation of which should be carried out not with tools of a repressive, but educational nature. It is thanks to the conscious choice of the optimal algorithm for the behavior of a person in the information and communication space that it is possible to protect information security in the virtual space. It is also important to take appropriate institutional and organizational measures to ensure the protection of the interests of individuals, society and the state in the virtual space.

\section{References:}

1. Law of the Republic of Uzbekistan «On Informatization».

2. https://runet.rbc.ru/

3. https://www.mlg.ru/

4. https://www.gazeta.uz/

5. https://pv.uz/ru/

6. https://hype.tech/

7. https://www.saferunet.ru/

8. www. statista.com

9. https://www.bbc.com/russian/features-52066878 